\title{
FIVE HUNDRED CASES OF MYALGIA IN THE BRITISH ARMY
}

BY MICHAEL GOOD

JUDGING by textbooks muscular diseases are very uncommon, but this is hardly in harmony with the fact that the musculature - the active locomotor apparatus-is the largest organ of the body. According to Sir Colin Mackenzie (1930) the animal body contains not less than 434 muscles, which constitute about 45 per cent. of the total weight, and the musculature contains about one-third of the total blood (R. J. S. McDowall, 1938). Further, one has to bear in mind that the muscles are subject for the greater part of the day to wear and tear, and from a purely theoretical point of view the muscles may be expected to be very liable to disease.

Muscular diseases are very frequent indeed, but their recognition has been delayed probably owing to the fact that they give rise to referred or heterotopic (D. Waterston) pain. This fundamental fact regarding muscle physiology has boen studied very recently-experimentally (Sir Thomas Lewis and I. H. Kellgren, 1938) and clinically (Good, 1938). The commonest muscular disease is myalgia, and is present in and responsible for pain complained of by the vast majority of people suffering from what is generally called rheumatism, and in a number of other minor diseases. Myalgia is a disease, the cardinal symptom of which is pain associated with more or less disturbance of function. Since the disturbance of functione.g., locomotion-is solely due to pain, which is aggravated by contraction of the affected muscle or muscles, myalgia may be looked upon as the prototype of the disease of pain (La maladie de la douleur, R. Leriche, 1932).

In such conditions pain is the outstanding symptom, but it is a subjective phenomenon; local tenderness, too, is solely subjective. Experience has shown that there exist normosensitive, hypersensitive and hyposensitive individuals or patients with regard to pain, indicating that the threshold of pain differs individually. In the case of myalgia the diagnosis can be based on objective phenomena.

Defintrion.-Myalgia is a muscular disease localised in welldefinable parts of a muscle and in its appendages-tendon, 
ligaments, perimysium, fascia-corresponding anatomically to the origin, insertion, the course or the edge of a muscle. It may affect one (monomyalgia) or several muscles (polymyalgia), and is characterised by the following symptoms:

Subjective Sians-1. Character of Pain.-A dull aching, sometimes agonising pain, occurring in attacks of a few minutes' duration or longer, with long intervals. The pain phenomena consist of two kinds-a deep pain, which cannot be localised properly, and a superficial type, which is localised, at least approximately, by the patient. The pain is aggravated by contraction and relieved by relaxation of the affected muscle or muscles. Sometimes it increases during sleep to such a pitch as to awaken the patient. Often pain or aching comes on in the early morning, when starting work, and slowly passes off.

2. Heterotopicity of Pain.-The painful areas as described by the patient are of a referred character, and therefore misleading with regard to the localisation of the diseased muscle.

3. Neuralgic Symptoms.-Paræsthesia; numbness, pins-andneedles are often complained of, especially in hands and fingers or feet and toes.

4. Disturbed Function.-Diminished or temporary loss of power in a special muscle or muscle group-e.g., dropping things from hands or giving way of knees. A very frequent complaint is stiffness, which seems to be akin to diminished strength of a muscle or muscle group.

The objective signs centre round what may be termed " myalgic spots," well and objectively defined areas at the origin, insertion, along the edge or in the course of a muscle, which as a rule are harder to the touch than the surrounding parts. Well-defined nodules may or may not be felt in the substance of the muscle (not to be confused with rheumatic subcutaneous nodules).

Objective Sians.-1. Pressure on a myalgic spot elicits a severe and agonising pain, which is often similar in character and extent to the spontaneous pain complained of.

2. Pressure on such a spot produces wincing pain associated with an involuntary movement-e.g., jerking of head or shoulder in a part of the body, not pressed upon, or the patient " makes a face." This sign is pathognomonic.

3. The myalgic spots, of which the patient is absolutely 
unaware, do not coincide with the painful skin area complained of, and in fact are often far removed from it.

4. In the area of referred pain, the skin is often hyperalgesic to pin-pricks and light pressure-e.g., from a hot-water bottle.

5. After appropriate treatment, applied to myalgic spots only, the local pain elicited by pressure, as well as the referred pain, disappears.

From a clinical point of view three different kinds of myalgia may be distinguished-viz.:

(a) Rheumatic myalgia, giving rise to pain referred to those parts of the body which are subject to rheumatism.

(b) Traumatic myalgia-cases where the complaint can with certainty be traced to a recent or previous injury, usually of an indirect nature.

(c) Idiopathic myalgia is of unknown origin and rather vaguely defined by negative criteria; it causes severe pain or ache in some parts of the body-heart, abdomen, feet, many forms of so-called neuritis-which are not supposed to be subject to rheumatism, nor due to an injury.

Myalgia may be an (1) acute, (2) subacute, or (3) chronic disease.

It must be borne in mind that both rheumatoid arthritis as well as osteo-arthritis are not rarely, and rheumatic fever commonly, associated with myalgic conditions in the muscles near to, or even at a distance from, the affected joints. Rheumatic myalgia, provided it is properly diagnosed and accurately located, is a disease which can be cured with certainty. For practical purposes it appears sufficient to describe here only the myalgias of those muscles which are most commonly affected.

Referred Pain From Muscle.-Before proceeding to the description of special myalgias the pain phenomena accompanying this very frequent muscular disease must be described. The most important point is that a diseased muscle, like a diseased viscus, may give rise to referred pain; this is conditional for the understanding of the symptomatology and the diagnosis of myalgias. From my experience as a patient $I$ can say that the pain phenomena consist of (1) a deep dull pain, which as a rule cannot be localised by the patient, and (2) a more superficial pain or paræsthesia, which may be localised, at least approximately. The latter is heterotopic or referred in character, is often localised far away from the affected 
muscle, especially in the thigh, and follows a segmental pattern. Clinical observations made over hundreds of cases have shown that pain, as mapped out by the patient himself, is delineated at least approximately on skin areas supplied by segments of the spinal cord-so-called dermatomes-and as a rule originates in muscles supplied by the same segments. This rule of dermatomes, although only approximately true, enables us to locate the myalgic spots in the muscles causing the pain or ache or stiffness complained of. The cutaneous areas of the skin innervated by the different spinal nerves are shown in Fig. 1. The localisation of the myalgic spots in the muscles most commonly affected is shown in Fig. 2.

Clinical Features of some Important Myalgias-TrapezoMyalgia (Myalgia of Neck).-Pain is usually referred to the neck and shoulder, but sometimes to the occiput extending to the top of the head. The skin areas of referred pain are C2 to C4. Pain is aggravated by movements of the trapezius and relieved by its relaxation. Trapezo-myalgia causes acute and subacute stiff neck and shoulder ache (case 1); sometimes it is responsible for occipital headache (case 2). It is usually rheumatic, but can often be traced to a trauma. It is noteworthy that giddiness is sometimes due to this form of myalgia: idiopathic myalgia of the trapezius, giving rise to muscular vertigo (case 3).

CASE 1.-Acute myalgia of trapezius:

November 15, 1941.-Driver H. (29) complained of dull ache in the nape of the neck, aggravated by movements of head or coughing. Myalgic spots (Fig. 3) located in both trapezii and injected with 6 c.c. of 1 per cent. procaine: immediate relief of pain, so that movements of head were practically painless.

November 17.-Slight pain in left shoulder still present; 3 c.c. injected.

November 19. - No complaints.

November 24.- - Returned to duty.

CASE 2.-Occipital headache:

July 9, 1941.-Gunner G. (20) complained of headache referred to the nape of the neck and extending to the top of the head, for a fortnight (Fig. 4). After injection of 3.5 c.c. of procaine into myalgic spots on both sides of the trapezius, immediate relief of pain. When seen a month later, he was without complaint.

Case 3.-Muscular vertigo:

June 16, 1941.-Private J. (26) has been complaining of dizziness for a fortnight. The dizziness occurs especially when getting up from a lying or bending position. Two myalgic spots in each trapezius were located and injected ( 5 c.c. of procaine).

June 18. - No dizziness. Not reported sick again in the following $2 \frac{1}{2}$ months. 
Omomyalgia (Myalgia of Shoulder).-Pain is usually referred to C4-5, rarely also to C6. Movements of shoulder are restricted, active and passive movements are extremely painful. This myalgia often simulates arthritis, periarthritis or bursitis of shoulder. Often the malady is of traumatic origin.

CASE 4.-Shoulder myalgia (Fig. 5):

November 10, 1941.-Gunner N. (22). For about 2 years pain and dull ache in both shoulders, occurring in attacks and improved by rest. Since a month pains have become much worse. Admitted to hospital for periarthritis. Myalgic spots in both trapezii and biceps tendons injected

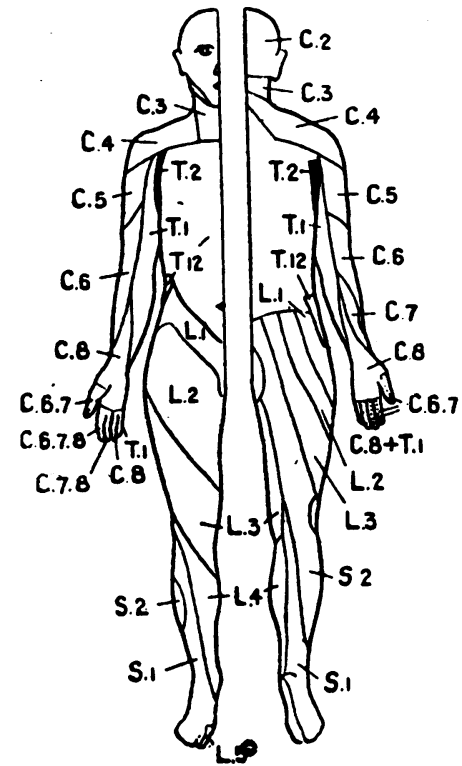

Fig. 1. (6 c.c. of procaine): immediate relief of pain and restoration of movements.

November 13. -1 c.c. of procaine injected. Returned to duty on November 19 after he had been without complaint for a week.

CASE 5.-Myalgia of shoulder and arm (Fig. 6):

November 12, 1941.-Gunner B. (30). Has been suffering for last 6-7 weeks from stiffness and pain in right shoulder and arm, worse at night and early morning. After 4 weeks of radiant heat treatment slight improvement, but very soon pain became worse. Myalgic spots in long head of biceps and heads of extensors of hand and fingers, injected ( 2.5 c.c. procaine).

On discharge (November 17, 1941) he said spontaneously: "The treatment has been wonderful."

CASE 6.-Traumatic myalgia of shoulder (Fig. 7) :

June 10, 1941.-Lieutenant R. (23). Fell on elbow the day before. Complained of severe pain in left shoulder and arm. Movements of shoulder and arm very restricted and extremely painful; 2.5 c.c. of procaine injected into myalgic spots located in long head of biceps.

June 12.-Pain still present; 3 c.c. injected into insertion of trapezius to scapula and one spot of biceps. Full relief of pain. Returned to duty June 16.

June 27.-No complaints.

Myalgia of Elbow (Cubital Myalgia).-Pain is referred to outer aspect of arm and hand and first to third fingers (external myalgia) or to the inner aspect of arm and hand and third to fifth fingers (internal myalgia). Myalgic spots can be located in the heads of extensors or flexors of wrist and fingers or in both. 

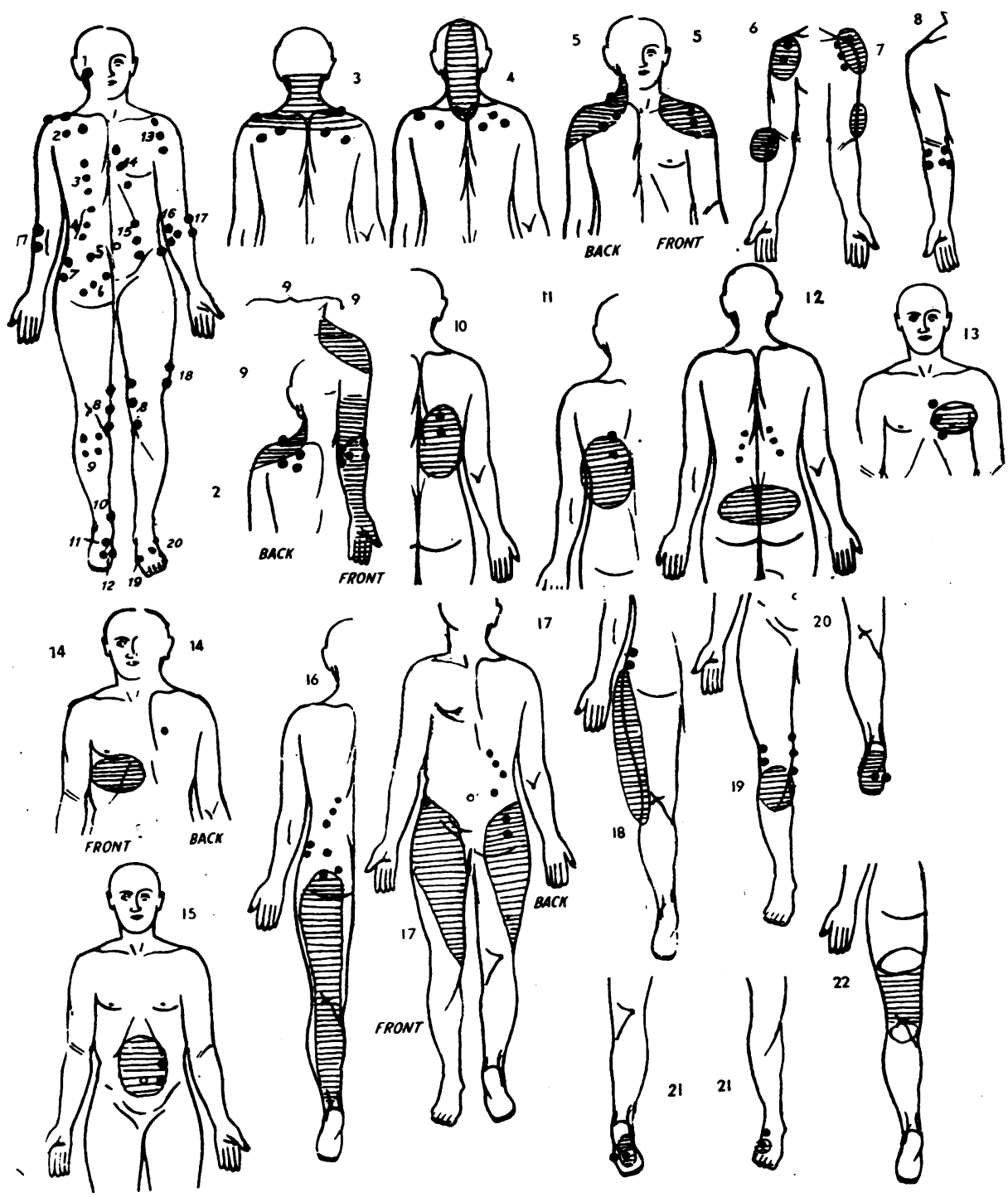

Fig. 2.-Myalgic Spots and Areas of Refrerked Pain.

The numerals in the following key refer to the figure in the diagram at the top lefthand corner; in the other figures the horizontal lines indicate the areas of pain as mapped out by patients and the dots the myalgic spots.

1. Sternomastoid.

2. Trapezius.

3. Sacrospinalis.

4. Quadratus lumborum.

5. Gluteus medius.

6. Gluteus maximus.

7. Tensor fasc. lat.
8. Semimembran.-tendin.

9. Gastrocnemius.

10. Tendo Achilles.

11. Flexor digitor. brev.

12. Flexor hallucis brev.

13. Biceps tendon.

14. Pectoralis major.
15. Rectus abdominis.

16. Flexors f of wrist and

17. Extensors $\}$ fingers.

18. Lateral vastus.

19. Ab́ductor hallucis.

20. Peroneus brevis. 
Sometimes the origin of the brachioradialis is also affected, and simulates what is often diagnosed "brachialgia." Cubital myalgia often gives rise to paræsthesia-pins-and-needles, numbness, etc.-and temporary loss of or diminished power-e.g., dropping things from hands-and may be present in and responsible for some cases of peripheral neuritis.

CASE 7.--Idiopathic myalgia of elbow (Fig. 8):

November 8, 1941.-Private S. (22). A year ago he developed pain in dorsum of right wrist and weakness of the forearm. The arm was strapped for 3 months and later kept in plaster of Paris for 5 months. No bony changes were found radiologically. Last 3 months he received massage and electrical treatment. On admission he complained of pain on dorsum of wrist and weakness of forearm and fingers, " no power of gripping." Myalgic spots were located in heads of extensors and flexors of hand and injected with 4 c.c. of procaine.

November 9.-1 c.c. injected into extensors. On physical training and remedial exercises.

December 12.-Discharged to duty. He reported 14 days later, when he was without complaint.

CASE 8.-Idiopathic myalgia of shoulder and elbow (" brachial neuritis "):

December 2, 1941. - Sergeant H. (37) was treated for brachial neuritis at P. Hospital from August 6 to October 31, at convalescent home from October 31 to November 21, and readmitted to P. Hospital November 21. His reflexes were normal; sensation left arm: light touch negative, pinpricks almost negative, heat and cold much diminished; Wassermann and Kahn negative. X-ray normal apart from slight rarefactions. He had been treated with massage, electricity, and betain (injections + tablets). On admission to the Military Hospital he complained of severe pains in left shoulder and anterior surface of arm (Fig. 9). Myalgic spots were located in left trapezius and extensors and flexors of arm.

December 3.- Injection of 6 c.c. procaine into myalgic spots, movements of shoulder, arm and fingers appear normal and painless.

December 8.-“ 45 per cent. improved." 4 c.c. of procaine injected. On physical training and remedial exercises.

December 24.-Still complains of pain. Examination: no myalgic spots. Seen by psychiatrist, who diagnosed psychogenic pain.

January 2, 1942.- - On questioning he agrees that he has improved up to 80 per cent. Objectively: movements of shoulder and arm appear normal.

January 7 , 1942.-Discharged to duty.

Dorsal and Lumbar Myalgias.-Pain is referred to the back below scapular spine down to the lumbar region, or to the small of the back. Pain is aggravated by stooping. bending and inspiration. Myalgic spots in the outer edges of the sacrospinalis on one or both sides may be responsible for high backache and for pleurodynia. Dorsal myalgia often simulates 
intercostal neuralgia and neuritis. In lumbago the myalgic spots are regularly found in the border of the quadratus lumborum, generally on the right and left, rarely they are only found on one side. The procaine injections in lumbago are best given in a tangential direction from the flanks, the patient sitting on a locker, with legs hanging down and arms crossed, but not supported by legs.

CASE 9.-Dorsal myalgia (Fig. 10):

August 19, 1941.-2nd Lieut. P. (28), for 6 months stabbing sharp pain in back, worse on lying down and getting up. Myalgic spots in sacrospinalis located and injected ( 3 c.c.).

August 20.-50 per cent. improved. One more spot injected ( 1.5 c.c.). Pain fully relieved.

August 21.-Reported to say that he is cured.

CASE 10.-Dorsal myalgia, simulating intercostal neuralgia:

July 13, 1941.-Gunner N. (29). Referred to me by his medical officer as suffering from intercostal neuralgia. Complains of pain corresponding to D6-7 on right, pain aggravated by inspiration. Two myalgic spots on outer edge of right sacrospinalis injected: immediate relief of pain.

July 15.-Reported cured.

Case 11.-Dorsal myalgia (Fig. 11):

August 12, 1941.-Gunner S. (27) complains of backache on left side; 3 c.c. injected into sacrospinalis with immediate relief of pain.

August 14.- Reported to have no complaints.

CASE 12.-Lumbar myalgia (lumbago):

December 25, 1941.-Major — has been suffering from lumbago for several months. Treated by radiant heat and massage, apparently with little relief; he was unable to localise his pain. Myalgic spots in right quadratus lumborum and one spot in right gluteus medius. Injected (10 c.c.) : pain immediately and greatly relieved (" up to 90 per cent.").

December 31.-No complaints.

January 16, 1942.-Ditto.

CASE 13.-Lumbago (Fig. 12):

November 12, 1941.-Pioneer W. (40) has been suffering from backache for last 3 months. Admitted because pain much worse last 3 days. Myalgic spots in quadratus lumborum on both sides injected (5 c.c.): pain immediately relieved, relaxation of cramped lumbar muscles.

November 19.-5 c.c. injected. On physical training.

November 26. -3 c.c. injected.

December 2.-On discharge no complaint for last week.

Precordial Pain.-Heart pain complained of by patients with a normal cardiovascular system is, as a rule, of muscular origin. Muscular pain referred by the patient to the heart may also be present in some organic diseases of the heart (M. G. Good, 1940). Two forms can be distinguished:

(a) Mammary pain. Pain is referred to a skin area-usually oval in shape-above or round the nipple, mostly on the left, 
but sometimes on the right side. The myalgic spots are as a rule found in the origin (ligamentous part) of the sterno-eostal part of the pectoralis major near the sternum, in the third to fifth intercostal spaces.

(b) Infr mammary pain. Pain is referred to an oval skin area below the nipples-right or left-sometimes also across the costal arch and upper part of the hypochondrium. Myalgic spots are localised in the outer edge of the sacrospinalis (right or left), and rarely in the origin of the pectoralis major from the lower ribs.

Both types of what is called by patients heart pain are aggravated by deəp breathing. Patients are therefore inclined to develop a type of shallow breathing.

CASE 14.-Left mammary pain (myalgia of pectoralis major) (Fig. 13):

May 9, 1941.-Gunner C. (30) complains of heartache for a fortnight, worse on breathing; 4 c.c. injected into myalgic spots at origin of pectoralis major : immediate relief of pain, even on deep inspiration.

May 12.- Heart pain gone. Not reported again.

CASE 15.-Right infra-mammary pain (Fig. 14):

July 28.-Gunner B. (29) complains of "heart pain" for a week. Pain referred to an area below right nipple. One spot in right sacrospinalis injected (2 c.c.) with instantaneous relief of pain.

July 30.-Reported to have no complaint.

Rectus Myalgia (Myalgia of Abdomen).-This form of myalgia is of great practical importance, since it gives rise to pain referred to the upper and/or lower abdominal region on the right or left, thus may simulate a visceral disease of the abdominal cavity. A very characteristic, almost pathognomonic feature is the point that pain is aggravated by bending and/or lifting heavy weights. The myalgic spots are usually localised in the outer border of the rectus abdominis in its upper or lower parts. It often is of unknown (idiopathic) origin, but sometimes can be traced with certainty to a trauma.

CASE 16.-Myalgia of rectus abdominis:

May 23, 1942. - Gunner T. (29) has been complaining of pain along left costal margin; treated with strapping, a contusion of rib being assumed to be responsible for the symptom.

May 26.- Not improved. Myalgic spot in left rectus located and injected ( 2 c.c.).

May 28. -50 per cent. improved. Two more spots in outer edge injected (1.5 c.c.). Pain fully relieved.

May 30.-Reported no complaint.

CASE 17.-Rectus myalgia, simulating gastric disease (Fig. 15): 
November 30, 1941.-Private D. (32). Since a boy of 10 he suffered from pain in stomach, especially after heavy meals-fish or greasy food. Attacks occurred every 2-3 months, lasting for a few days or sometimes 3-4 weeks. Attacks occurred when he happened to be in a depressed mood. About 7 weeks ago, after having been detained in barracks, he developed stomach pain, starting an hour after meals-fish or fried food -lasting for varying periods. Pain increased on lifting heavy weights. $X$-ray of stomach and other tests were negative. Two myalgic spots located in left rectus abdominis and injected with 2 c.c. of procaine.

December 17.-Discharged to full duty, after his gastric complaints had been absent for 14 days.

Sciatica (a Myalgia of Hip).-The syndrome of sciatica is in the vast majority of cases caused by a polymyalgia of hip muscles (coxal myalgia). The myalgic spots are, as a rule, localised in the quadratus lumborum, glutei and tensor fasciæ latæ. Muscular sciatica seems to be a suitable designation of this form of the malady, in contrast to true or nervous sciatica, which in my experience is rare. The explanation of the fact that a myalgia of the hip muscles just mentioned causes pain referred to the posterior aspect of thigh and leg is apparently due to the rule of dermatomes: the quadratus lumborum is supplied by L1-4, gluteus maximus by L4-5 and S1-2, gluteus medius and tensor fasciæ latæ by L4-5 and S1-viz., segments of the cord supplying the posterior aspect of the leg (Fig. 1). Muscular sciatica can be cured with certainty by appropriate injections of procaine into the accurately located myalgic spots. It is noteworthy that in hip myalgia pain may be referred to thigh and groin only, although the myalgic spots are almost the same as in sciatica.

CASE 18.-Sciatica due to hip myalgia (Fig. 16):

November 8, 1941.-Driver B. (36). Sciatic pain in left leg for last 7 months; treated at a C.C.S. hospital for 6 weeks with heat and massage Slight improvement. Pain much worse of late. Examination: Lasègue's sign positive on left, ankle jerk absent on left; myalgic spots located in quadratus lumborum, glutei and tensor fasciæ latæ and injected with $\tilde{5}$ c.c. of procaine: pain immediately disappeared and movements of left leg were painless.

November 10.-Complained of pain over left calf. Two myalgic spots in yastrocnemius injected $(2 \cdot 5$ c.c.).

November 13.-No pain although on physical training.

Up to his discharge (November 28) he was treated for moderate hyperpiesis, but sciatic pain was absent since last injection.

CaSE 19. - Sciatica (Fig. 17):

November 12, 1941. - Sergeant M. (37). Suffered from malaria (1932) and twice from sciatica 1 and 2 years ago respectively. Admitted to hospital 
for right sciatica. Treatment with aspirin and radiant heat only slightly improved.

November 26.-Transfer to rheumatism ward. Examination: welldeveloped scoliosis; on standing he puts body weight to left leg. Lasègue's sign positive. Reflexes normal. Myalgic spots located in quadratus lumborum, glutei and tensor fasciæ latæ injected (6 c.c. of procaine), After injection the quadratus lumborum, which was cramped before. relaxed and patient could touch toes without discomfort.

November 29. - Pain on anterior aspect of leg still complained of and slight scoliosis still present; 5 c.c. of procaine in right quadratus lumborum and gluteus medius injected.

December 4.-No complaint, but quadratus lumborum still contracted; 2 c.c. injected.

December 6.-After injection of 2 c.c. muscle fully relaxed. On physical training.

December 17.-Return to duty. August 15, 1942.-No complaints.

CASE 20.--Sciatica :

Surgeon Lieutenant (36). Septic tonsillitis and rheumatism-fibrositis and arthritis of spine-some years ago. For a week severe agonising sciatic pain in right leg. After injection of 6 c.c. of procaine into tensor fasciæ latæ and gluteus medius instantaneous relief of pain. Next day he noticed slight discomfort at site of injection. Pain did not recur during following 3 months.

Myalgia of Tensor Fascice Lato.-Monomyalgia of this muscle is often due to an injury, usually of an indirect nature. The myalgic spots are generally found in the origin from the anterior superior spine and the border of its upper muscular part at the outer aspect of thigh. Pain is referred to the outer aspect of legs and is greatly increased on standing, walking or bracing the injured leg. The results of procaine injections are often very remarkable.

CASE 21.-Traumatic myalgia of tensor fasciæ latæ (Fig. 18):

May 14, 1941.-Gunner O. (29). Kicked leg a fortnight ago while playing hockey. Three days later he developed pain at outer aspect of right leg, unable to walk. After injection of 3 c.c. into origin of tensor fasciæ latæ instantaneous relief and restoration of movement. He played hockey 2 days after treatment, to his and his sergeant's great surprise. I saw him a fortnight later, when he had no complaint whatsoever.

Myalgia of Knee.-This is a very common malady. Pain is referred to a circular or oval area round or below the patella, or rarely to the popliteal space. The myalgic spots are localised in the border of the lower half of the semimembranosus-tendinosus and sometimes also in the lateral edge of lower part of vastus lateralis. Myalgia of knee is present in many diseases which are often diagnosed arthritis, osteo-arthritis, chronic synovitis, etc. In doubtful cases procaine injection may be used as a diagnostic 
test to prove conclusively that a given pain and disturbance of movements are of muscular origin. In addition, it may be found that the treatment leads to a rapid cure, provided objectively defined myalgic spots, but not just " tender spots," said to be painful on pressure by patients, are thoroughly injected.

CASE 22:-Myalgia of knee (Fig. 19):

June 25, 1941.-Pilot Officer P. (53). For the last 20 years rheumatism in both knees. A few weeks ago treated at a naval hospital for arthritis with no improvement. Examination: distinct creaking in left knee on movements. Myalgic spots in semimembranosus-tendinosus on both sides and in vastus lateralis of left knee; 5 c.c. of procaine injected (left knee).

June 27.-No pain in left knee; 3 c.c. injected into right knee.

June 28.- "Very pleased; never felt so well in whole life."

Case.23.-Traumatic myalgia of knee:

May 31.-Sergeant H. (26). $2 \frac{1}{2}$ months ago he suffered from locking of right knee, due to an injury. He was operated on (removal of cartilage). Since the operation he has been suffering from pain in knee, especially on walking. He was seen by the orthopædic surgeon, who diagnosed " chronic synovitis," and his discharge from the Army was under consideration by a Medical Board. A myalgia of knee was detected. After injection of 5 c.c. of procaine into semimembranosus-tendinosus muscle there was immediate relief of pain and restoration of function.

June 7.-No complaint. Three weeks later he appeared before the same Board and said that he had been on full duty since the treatment and bad no complaints whatever. He was categorised Al.

Painful Feet (Myalgia of Foot).-This condition is extremely important from the military point of view. Many men report sick because of the syndrome of painful feet. The complaints are of a dull ache or burning pain : on the plantar or dorsal surface of the foot, on standing, and especially on marching. From a recent publication of Capt. R. T. Burkitt (1941) I cite the following sentences: "The condition of flat-foot in all its varying degrees is by far the commonest cause of doubtful efficiency. The 'severe' form in which the head of the talus has gone right over and the flatness is ' complete' causes least trouble. Some men with this condition are placed in a category barring them from an infantry regiment. Of those who are not the majority have no trouble with their feet at all; they can perform long route marches.... It is a recognised fact that the severest pain is always caused by the high arched foot beginning to give way. ... Any case which fails to respond to treatment (i.e., conservative M. G.) within three weeks should be 'boarded out' without delay." The author mentions the interesting fact that in his battalion 30 men 
reported sick with symptoms caused by fallen arches. But there were 33 other men in the same unit with a marked degree of flat-foot, as evidenced by footprints and appearance, who never complained although they had been for route marches. The results of 30 treated cases were: " 17 probable failures out of 26 followed-up cases "-i.e., 65.39 per cent. failures.

From my own experience in the Army I can confirm Burkitt's view : complaints of painful feet are mostly due to flat-feet, but sometimes to pes cavus. Moreover, many officers and other ranks never complain of foot troubles in spite of fallen arches. From this fact one must, in my opinion, draw the conclusion that falling of the arches may be neither the cause nor the origin of the syndrome of painful feet. In all the cases examined by me (about 40 cases) an objectively definable disease - myalgia - of foot muscles could be ascertained. The myalgic spots are usually localised in the course, or mostly in the insertion, of flexor brevis hallucis, the insertion of the Achilles tendon to the calcaneum and the flexor brevis digitorum in the middle of its course. Here, too, the injection of procaine into the accurately located myalgic spots serves as a diagnostic test, which proves conclusively that the pain complained of is of a referred nature and of muscular origin. The following short case-histories will show that procaine injection is a simple and reliable method which enables us to control pain permanently and restore function in a short time.

CASE 24.-Myalgia of foot (Fig. 20):

June 21, 1941.-Gunner I. (21). Complained of pain in feet, especially on standing and marching. Examination: pedes plani, myalgic spots at the insertion of flexor brevis hallucis. Right foot injected (2 c.c.).

June 23.-No pain in right foot. Left foot injected (3 c.c.).

June 25.-No complaints; not reported again, although ordered to do so if pain recurred.

CASE 25.-Myalgia of foot (Fig. 21):

June 26, 1941.-Bombardier B. (25). Complained of pain under right foot. Arch normal, but myalgic spots at insertion of flexor brevis hallucis located and injected (2 c.c.).

June 27.-80 per cent. improved; myalgic spots at insertion of peroneus brevis injected ( 2 c.c.).

June 28.-No pain.

June 30.-No complaints.

Aggravation and Simulation of Pain.-Under present extraordinary conditions of a nation in arms, it has to be borne in mind that complaints may be exaggerated or even simulated, because they may subconsciously-or in case of a malingerer 
consciously-be intended to serve a special purpose. Looked at from a psychological point of view, such a behaviour of a soldier or factory worker can be understood, although not approved of (" tout comprendre, n'est pas tout pardonner," under abnormal conditions!). Psychologically it can be understood that a soldier or worker who has been doing a tricky, dirty or generally unpleasant job dreams of a temporary break and of a peaceful rest in a hospital. Small wonder, that he may subconsciously be inclined to aggravate a slight or moderate pain, which he happens to feel, in order to excuse himself before his conscience for trying to shake off temporarily or for a longer period his duties towards his country.

The modern diagnotis of myalgia is based on objective criteria which, I think, enable us to distinguish with great probability or with certainty between a genuine complaint and exaggerated or simulated symptoms. The characteristic signs are:

(1) Delineation of pain: glove and stocking types of pain, or pain extending round a whole limb.

(2) Pseudo-myalgic spots. If a pressure is exercised on an area of supposed referred pain, but not a myalgic spot, the patient gives a jerking of a part of his body. Moreover, this reaction is exaggerated-e.g., the jerking is repeated several times-and delayed-i.e., a few seconds elapse before the reaction occurs. During the time interval one distinctly feels a voluntary contraction of one or several muscles situated round the pressed-upon area. In contrast to that, the reaction of a genuine patient is immediate and consists of one jerk only. But a necessary precaution is to demonstrate to the patient the difference between a "sharp pain " elicited by pressure on a true myalgic spot and a pain produced by the same pressure on a normal muscle or bone. It must be emphasised that a diagnosis of exaggeration or simulation of pain should be made only after several very thorough examinations have led to the same result; and if there is any doubt the patient should be given the benefit of it.

CASE 26.-Simulation of pain (Fig. 20):

July 9, 1941.-Gunner T. (32). Complains of pain of a stocking type between knee and middle of upper leg. A very thorough examination did not reveal any myalgic spots. In addition the man showed a repeated and exaggerated jerking of head on pressure on quadriceps or patella. He was returned to duty and did not report sick again in the next 6 weeks.

The cases referred to in this article were seen by me partly at a main dressing station and several medical inspection rooms 
and partly in a rheumatism ward of a military hospital. The vast majority were treated very successfully by procaine injections; a small percentage of the cases refused this treatment. Table I shows the distribution of myalgias over the different regions of the body, classified under the heading of rheumatic, traumatic and idiopathic. In the table all sciatica cases are included under myalgias of hip, the conditions of painful feet under idiopathic myalgias of leg, unless a traumatic origin could be ascertained. It is interesting to note that myalgia of leg was the most frequent malady, next in frequency were the myalgias of hip, dorsal+lumbar region, and neck, diminishing in that order.

Table I.-Statistics (500 Cases).

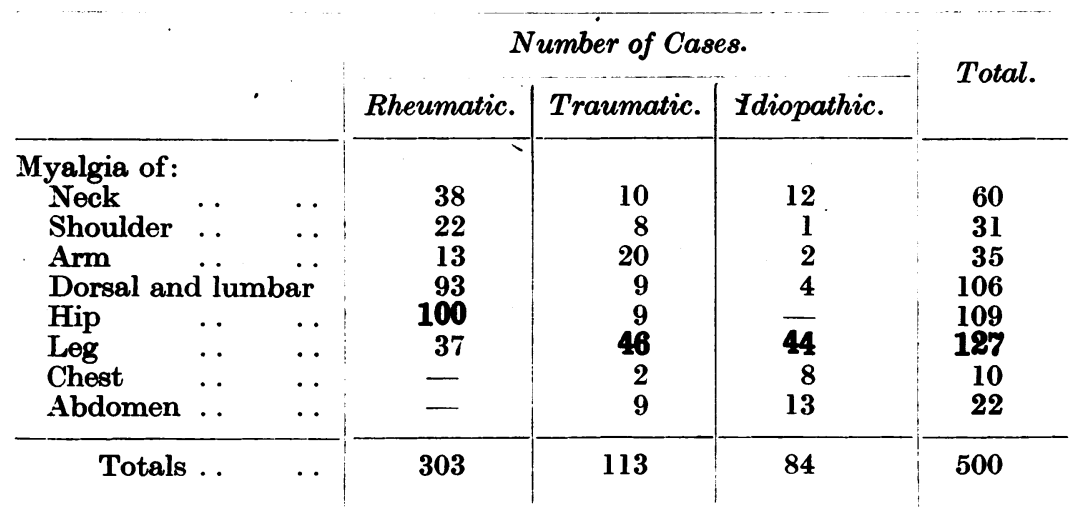

A very interesting fact emerging from Table II, which shows the frequency of individual muscle involvement, is that the quadratus lumborum and trapezius are most frequently diseased, next in frequency being tensor fasciæ latæ, glutei, semimembranosus tendinosus and sacrospinalis, in that order. No myalgias were met with in the triceps, the adductors and extensors (except lateral vastus) of the leg. An explanation of the frequency of myalgias of the first seven muscles of Table II is suggested by distinguishing between two functions of a muscle. E. Bramwell (1925) has drawn attention to this distinction when dealing with primary muscular dystrophies. This author states that the distribution of muscular involvement in muscular dystrophies suggests that muscles which are of special importance as fixators in relation to maintenance of posture are predisposed; whereas muscles more especially concerned with active purposive movements, of which we are more directly conscious, are either spared 
or affected only at a later date. It would appear that this explanation holds good also for the relative high incidence of involvement of quadratus lumborum, trapezius, sacrospinalis and tensor fasciæ latæ, which, to a large extent, are fixators. According to Bramwell the muscles of the thigh play an important part as fixators in running. Probably the semimembranosus tendinosus plays a similar and equally important rôle as a fixator of knee.

Table II.-Frequency of Individual Muscles Involved.

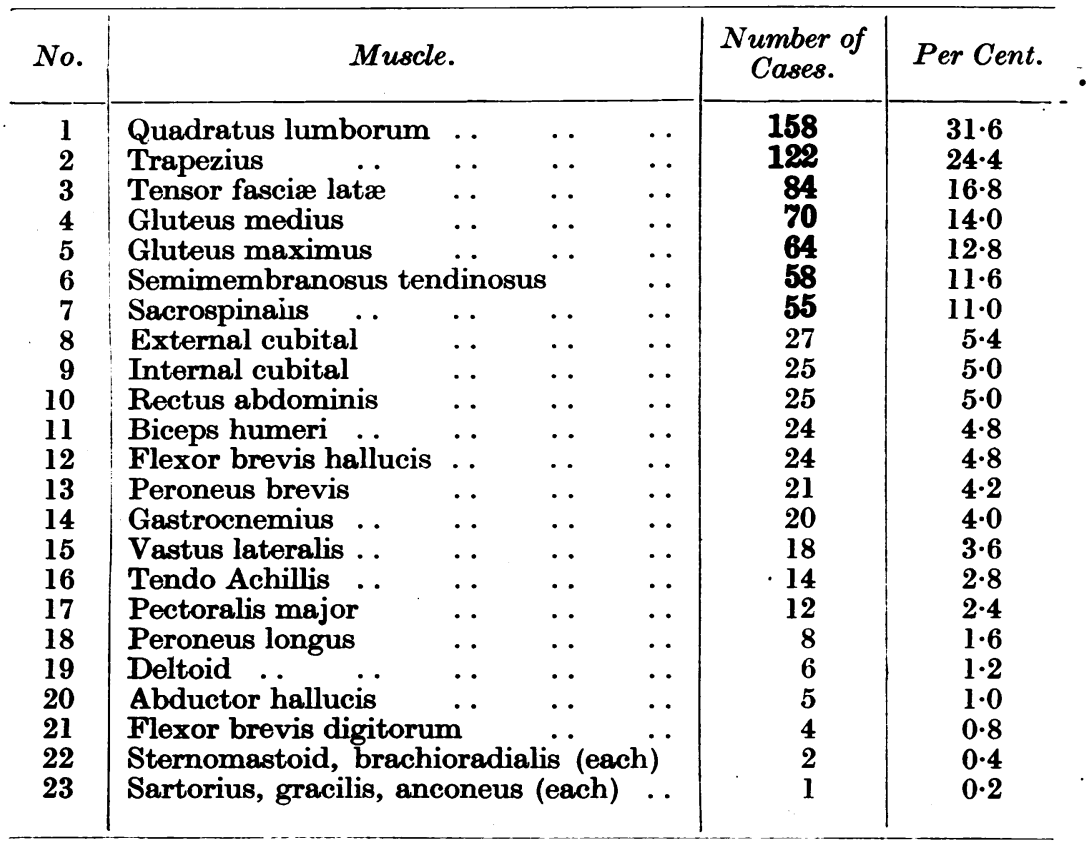
affected.

N.B.-Every muscle was counted only once, even if both sides were

Ettology and Pathology.-The primary cause (or causes) of rheumatic myalgias is not known. But in the opinion of most clinicians the following factors play a rôle as an exciting cause: 1, septic foci; 2 , allergic conditions; 3 , climatic conditions; 4, endocrine dysfunction (thyroid, sex glands); 5 , trauma; and 6, mental worries and emotional strain. In my opinion 7, an " autonomic imbalance," either in the form of predominance of the sympathetic-sympathicotonia-or of the parasympathetic-vagotonia-and probably also. 8, an imbalance 
of electrolytes, especially of the $\mathrm{Na}: \mathrm{K}:$ Ca ratio, may be important contributing factors. Experience in the Army has shown that in a great number of cases-22.6 per cent. of all cases as shown in Table I-myalgias could with certainty be traced to a recent or previous injury.

The pathology of myalgias is at present very obscure. $R$. Stockman (1920) has described the pathology of "nodules" which he took to be responsible for fibrositis. Stockman found that the "nodules" consist of inflamed white fibrous tissue and that the small blood vessels often show very distinct thickening of all their coats, as if they had suffered from the action of an irritant. But it is necessary to point out that in the majority of myalgias " nodules" are conspicuous by their absence. In my experience a hard nodule is often found in the heads of the flexors of wrist and fingers in cubital myalgia. But in other cases the myalgic spots are harder to the touch than the surroundingi.e., the muscular area is in a spastic condition. This can best be seen in lumbago, where the quadratus lumborum is contracted; on appropriate injection of procaine the muscle relaxes almost instantaneously. Moreover, nodules in the substance of a muscle are often found in healthy subjects who have no complaints whatever. In my opinion the conclusion is justified that nodules are generally not responsible for myalgic conditions. In a recent publication (1942) E. J. Moynahan and E. S. Nicholson confirm that " nodules were not a constant feature of the malady clinically: they are absent more often than not." For this very reason fibrositis is by no means an adequate term for the malady, which is a muscular disease, localised in anatomical parts of a muscle (Good, 1938). If an inflammatory condition were present it should be termed interstitial myositis. But since the inflammatory process is very much in doubt, it would appear more appropriate to call it for the present myalgia or myopathy of rheumatic, traumatic or idiopathic origin. It is a fact that injection of 1-2 c.c. of 1 per cent. procaine abolishes the myalgic spot definitely and permanently. But it is extremely unlikely that a local anæesthetic will cure an inflammatory process in a muscle or any other organ without delay.

On the other hand the common denominator of the contributory factors of myalgia mentioned above may be looked for in a disturbance of the local blood supply. As a work- 
ing hypothesis the conception of a diminished blood supply confined to the myalgic areas is tentatively put forward, leading to oxygen want-local hypoxæmia or hypoxia-which would account for the characteristic symptoms of myalgias-viz., pain, paræsthesia and loss of power (Good, 1938). Such a "vasomotor disequilibrium" (Leriche, 1930) may be brought about by stimulation of vaso-constrictor sympathetic fibres. It is noteworthy that adrenaline, the action of which is often identical to stimulation of the sympathetic, has a dual effect on the blood vessels of the muscles, which are dilated by small doses and constricted by large ones (McDowall, 1938). R. Pemberton (1935) has put forward the same conception of disturbed circulation for articular rheumatism and brought forward evidence in support of this view.

Treatment.-A rapid, effective and permanent cure can be obtained by injections of procaine into the myalgic spots.

Solution used:

$$
\begin{array}{llllllr}
\text { Procaine } & \ldots & \ldots & \ldots & \ldots & \ldots & 1.0 \\
\underset{\text { Phenol }}{\text { Saline }} & \ldots & \ldots & \ldots & \ldots & \ldots & \mathbf{0 . 5} \\
& \ldots & \ldots & \ldots & \ldots & \text { ad } 100.0 \text { c.c. }
\end{array}
$$

S.: Sterile in rubber-capped bottle.

Technique.-The myalgic spots are mapped out on the skin with a blue dermatograph, the pencil marks painted over with iodine and 1-2 c.c. of 1 per cent. procaine solution injected intramuscularly into each spot, care being taken to infiltrate the whole myalgic area. The result of a thorough and accurate injection are: (1) almost instantaneous relief of pain; (2) relaxation of the spastic muscle, as evidenced by palpation; and (3) pressure on the myalgic spot no longer elicits pain or produces a wincing or involuntary jerking. In this way marvellous, sometimes fantastic results are obtained, which must appear almost incredible to those who have not used the method or seen its effects. Few things in clinical medicine can be more dramatic than to obtain in a patient, who is in agony and doubled up, an almost instantaneous relief of pain and restitution of the disturbed function of the diseased muscles after injection of procaine. But a proviso has to be added-these extremely favourable results will not be obtained by injection of spots tender to pressure-i.e., the patient complains of pain on pressure, a "subjective" sign only. Moreover, sensitiveness to pain differs very much individually, as mentioned above. A myalgic spot objectively located and 
once properly injected no longer gives rise to complaints. A myalgia can be and often is cured by one treatment; if complete cure is not obtained, it is due to one of the following reasons: (1) not all myalgic spots were injected; (2) a faulty technique with regard to location of myalgic spots or injection; or (3) exaggeration of pain by patient.

Owing to lack of space the theory of the procaine effecti.e., why a local anæsthetic should relieve permanently pain arising from a myalgic spot cannot be discussed here. The discussion of this question, which is intimately connected with the theory of pain, would require a special article.

Table III.-Analysis of 230 Cases of Myalgia.

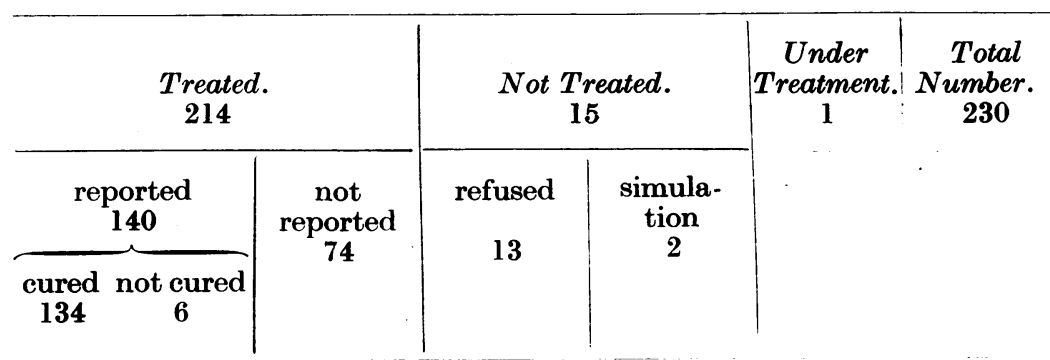

The analysis refers to cases $I$ have seen in a place, somewhere in England, where I was posted for a longer period and was in a position to verify the results. Of the 230 officers and other ranks who suffered from myalgias 15 received no treatment, mostly because injections were refused; a few of these men were markedly improved after one or two injections, but refused further treatment on the ground that in their opinion the injections did not do them any good; 2 men were given no treatment because I was satisfied that their complaints were not genuine.

Of the remaining 214 cases, who were treated by procaine injections only, 134 reported "cured"-i.e., they had no symptoms, pain or disturbance of function; 6 men reported " not cured"-i.e., some had, although improved, still symptoms, and a few said they had derived no benefit from the treatment. All these cases were given a very thorough examination, and I was satisfied that the symptoms were exaggerated. They were returned to full duty and have not reported sick again in the next one to three months; 74 cases have not reported after the last treatment, although ordered to do so. On enquiry the medical 
officers concerned confirmed that the men had not reported sick again. Taking an unprejudiced view it may be assumed that the 74 not-reported cases were cured, or at least so much improved that the men did not think it worth while to report again, though 5 men reported sick after one to three months with the same complaints, but were cured by one or two or more treatments. Among the cases were 26 of foot myalgia; the results of procaine injection were as follows: 4 men refused the treatment; of the 32 officers and other ranks treated 13 reported cured, and 9 men did not report after the last treatment, although ordered to do so in two days.

\section{SUMMARY}

Myalgia is a very frequent disease localised in certain anatomical parts of one or more muscles. Its characteristic features are " myalgic spots" which can be located by objective criteria and give rise to referred or heterotopic pain. Myalgia is present in and responsible for the vast majority (according to statistics 95 per cent.) of patients suffering from rheumatism; it is not rarely associated with rheumatoid arthritis, osteo-arthritis, and commonly with rheumatic fever. The malady is also responsible for a number of minor diseases which can be traced to an injury - traumatic myalgia. It is often of unknown origin-idiopathic myalgia - and mimics visceral and nervous diseases (heart pain, neuralgia or neuritis, sciatica, syndrome of painful feet, etc.). The localisation of the myalgic spots-the characteristic features of myalgias of neck, shoulder, arm, back, lumbar region, hip and leg-is described. Procaine injection into the accurately and objectively located myalgic areas is warmly recommended as relieving pain and other complaints in a most dramatic way and as leading to a rapid cure.

\section{REFERENCES}

BurkitT, R. T. (1941): Brit. Med. Journ., 1, June 28.

BramWell, E. (1925): Lancet, 2, 1103.

DeJerine, J. (1926): " Sémiologie du système nerveux," Paris, p. 302.

Good, M. G. (1938): Brit. Journ. Phys. Med., N.S., 1, 302.

GooD, M. G. (1940): Ibid., 3, 50.

Good, M. G. (1940): Lancet, 2, 326.

Good, M. G. (1941): Practitioner, 146, 167.

GooD, M. G. (1942): Ibid., 148, 236.

Good, M. G. (1942): Journ. R.A.M.C. (in the press).

KellgRen, J. H. (1938): Brit. Med. Journ., 1, 325. 
Leriche, R. (1930): Presse Méd., 38, 417.

LeRICHe, R. (1939): “The Surgery of Pain,” ed. by A. Young, London. Lewis, Sir Thomas (1938): Brit. Med. Journ., 1, 321.

MACKEnzIE, Sir CoIIn (1930): “The Action of Muscles," London, p. 1. McDowall, R. J. S. (1938): "The Control of the Circulation," London, pp. 31, 64, 268.

Moynahan, E. J., and Nicholson, E. S. (1942): Brit. Med. Journ., 1, 65. Pemberton, R. (1935): “Arthritis and Rheumatoid Conditions," London. Stockman, R. (1920): “ Rheumatism and Arthritis,” Edinburgh, p. 42.

\section{EMPIRE RHEUMATISM COUNCIL}

\section{SIXTH ANNUAL REPORT}

My Lords, Ladies and Gentlemen,

Is submitting the Annual Report for 1942, I express again my regret that it has been considered inadvisable by the War Emergency Committee to convene the Annual Meeting. To. have asked our members, some 150 in number-practically all engaged in work of national importance, and many living at a distance from the metropolis - to meet in London would have been a trespass on energy which must be conserved for the effective prosecution of the war.

Our President, H.R.H. the Duke of Gloucester, acknowledging the Report for 1941, expressed his pleasure that "thanks to prompt action in sending out missions of enquiry to the Rheumatism Treatment Centres of America and Europe before the outbreak of war, you are now able to present a plan of treatment based on the international as well as British practice." He also warmly welcomed the close connection established with the American Rheumatism Association, writing: "In this field of humane effort, as in so many others, the best hope for the world rests with the friendly co-operation of the English-speaking peoples."

Another development in the integration of our war on rheumatism is to be recorded - the conclusion of an agreement with the British Orthopædic Association. This can contribute greatly to the efficiency of practitioners in the diagnosis and treatment of crippling conditions caused by rheumatic diseases and also to national economy. A joint policy was unanimously agreed at a conference of representatives of both bodies in June. It is as follows : 